\title{
Analisis Perubahan Faktor Keamanan Lereng Akibat Hujan
}

\author{
(Analysis of Changes Safety Factor of Slope Due to Rainfall)
}

\author{
Achmad Hafidz ${ }^{*}$, Muhammad Fauzan ${ }^{1}$, Heriansyah Putra ${ }^{1 *}$, dan Annisa Daniswara \\ Santoso $^{2}$ \\ ${ }^{1}$ Departemen Teknik Sipil dan Lingkungan, Fakultas Teknologi Pertanian, Institut Pertanian Bogor. \\ J1. Raya Dramaga, Kampus IPB Dramaga, PO BOX 220, Bogor, Jawa Barat Indonesia \\ ${ }^{2}$ Departemen Geografi, Fakultas Matematika dan Ilmu Pengetahuan Alam, Universitas Indonesia. \\ Jl. Margonda Raya, Kampus UI Depok, Depok, Jawa Barat Indonesia \\ *Penulis korespondensi: achmadhafidz27@gmail.com (AH); heriansyahptr@apps.ipb.ac.id (HP)
}

Diterima: 02 Juli 2019

Disetujui: 08 Agustus 2019

\begin{abstract}
Infiltration causes a decrease in soil shear strength parameters. Decrease in soil shear strength parameters can cause landslides. Landslides often occur in Bogor Regency, one of the landslide locations is Puncak, Bogor. Landslides in Puncak, Bogor on 05 February 2018 at 09.20 WIB must have a safety factor 1.07. Changes in safety factors due to rainfall are observed from 03 February 2018 at 05.00 WIB until 05 February 2018 at 09.20 WIB. This research includes testing soil samples, pore water pressure analysis and slope stability analysis. The software used for this analysis is GeoStudio. The analysis results are the changes in safety factor due to rainfall. The safety factor on 03 February 2018 at 05.00 WIB is 1.602. Safety factor until 05 February 2018 at 03.40 WIB are still above 1.25. So, the slopes are still safe. The decline in safety factor continued until 1.070 due to a decrease in cohesion on 05 February 2018 at 09.20 WIB with cohesion on $S W-S M$ soil and SM soil at $4.01 \mathrm{kPa}$ and $9.18 \mathrm{kPa}$. So, the duration needed to change a safe slope to landslide is only 5 hours 40 minutes. This can occur because of the intensity of the rain on 05 February 2018 at $07.00 \mathrm{WIB}$ and $08.00 \mathrm{WIB}$ are $34.1 \mathrm{~mm} / \mathrm{hour}$ and $34.9 \mathrm{~mm} / \mathrm{hour}$.
\end{abstract}

Key words: cohesion, landslides, rainfall, safety factor

\section{PENDAHULUAN}

Air hujan yang membasahi permukaan tanah akan mengalami infiltrasi ke bawah permukaan tanah. Infiltrasi air hujan ini disebabkan oleh adanya tarikan gaya gravitasi (Hutabarat et al. 2015). Infiltrasi air hujan ini menyebabkan penurunan parameter kuat geser tanah (Hasrullah 2012). Kuat geser tanah terdiri dari dua parameter tanah yaitu kohesi (c) atau gaya tarik-menarik antar partikel dan sudut gesek dalam $(\varphi)$ atau gesekan antara butir tanah (Nugroho et al. 2012). Penurunan nilai kohesi tanah ini disebabkan oleh penurunan jarak antar butiran partikel tanah akibat peningkatan jumlah air yang mengisi rongga pori tanah. Peningkatan jumlah air yang ada dalam pori tanah menyebabkan derajat kejenuhan menjadi meningkat, sehingga tegangan air pori yang berlebih akan terbentuk (Hasrullah 2012).

Penurunan parameter kuat geser tanah ini dapat menyebabkan tanah longsor (Nurdian et al. 2015). Menurut Suryolelono (2002) dalam Apriyono (2009), tanah longsor merupakan fenomena alam yang berupa gerakan massa tanah dalam mencari keseimbangan baru akibat adanya gangguan dari luar. Tanah longsor merupakan salah satu bencana yang cukup sering terjadi di Kabupaten Bogor. Longsor yang terjadi di Kabupaten Bogor mencapai 102 kejadian dari bulan Januari hingga Juni 2018 (BPBD 2018). Salah satu lokasi di Kabupaten Bogor yang mengalami longsor adalah Puncak, Bogor. Pada tanggal 05 Februari 2018, longsor terjadi di 4 lokasi di Puncak, Bogor.

Longsor yang terjadi pada 05 Februari 2018 pukul 09.20 WIB di Puncak, Bogor disebabkan oleh faktor keamanan lereng yang telah lebih kecil dari 1.07. Hal tersebut 
dapat terjadi karena faktor keamanan lereng yang kurang dari 1.07 pasti akan mengalami longsor (Bowles 1979). Faktor keamanan ini memiliki hubungan dengan nilai kohesi. Menurut Rouaiguai et al. (2018), faktor keamanan ini dipengaruhi oleh nilai kohesi, karena peningkatan nilai kohesi secara linier akan meningkatkan faktor keamanan. Oleh karena itu, penelitian ini bertujuan untuk mengetahui perubahan faktor keamanan lereng akibat hujan hingga lereng di Puncak, Bogor menjadi longsor.

\section{METODOLOGI}

Penelitian ini dilakukan di Puncak, Bogor, Jawa Barat. Alat yang digunakan adalah software GeoStudio 2012. GeoStudio adalah software yang menggunakan analisis numerik yang dikembangkan oleh GeoSlope International untuk geo-engineers dan earth-science. GeoStudio ini terdiri dari beberapa aplikasi seperti TEMP/W, SEEP/W, CTRAN/W, AIR/W, SIGMA/W, QUAKE/W dan SLOPE/W (GeoSlope 2017). Dua aplikasi digunakan pada penelitian ini yaitu SEEP/W dan SLOPE/W. Aplikasi SEEP/W digunakan untuk menganalisis perubahan tekanan air pori pada lereng (Putra et al, 2017; Subiyanti et al. 2011). Sedangkan, SLOPE/W dapat digunakan untuk menghitung faktor keamanan lereng tanah maupun batu (Putra et al, 2016; Atikah et al. 2017).

Penelitian ini dilakukan dengan beberapa tahapan, mulai dari studi lapangan, analisis data tanah, analisis tegangan air pori, dan analisis stabilitas lereng. Studi lapangan yang dilakukan berupa survei dan observasi lapang untuk memperoleh data primer dan data sekunder yang akan digunakan pada tahap analisis. Data primer yang digunakan berupa data propertis dan kuat geser tanah serta geometri lereng sebelum dan sesudah terjadinya longsor. Sementara itu, data sekunder berupa data curah hujan jam-jaman tahun 2018 wilayah Puncak Bogor yang diperoleh dari stasiun meteorologi Citeko.

Sampel tanah yang digunakan untuk pengujian laboratorium pada penelitian ini diambil di dua titik pada lokasi longsor di Puncak, Bogor. Kedua titik sampel ini mewakili lapisan tanah yang ada di lokasi longsoran. Selanjutnya, sampel tanah diuji di laboratorium dengan alat uji geser langsung untuk memperoleh parameter kuat geser tanah berupa nilai kohesi (c) dan sudut geser dalam $(\varphi)$ pada saat jenuh, pengujian kadar air lapangan, kepadatan lapangan dan permeabilitas saat tanah jenuh, analisis saringan, penentuan batas Atterberg dan specific gravity. Sedangkan, pengukuran geometri sebelum dan sesudah longsor menggunakan electronic total station (ETS). Geometri lereng sebelum longsor diperoleh dari pengukuran lereng disebelah lokasi longsor. Sedangkan, geometeri lereng setelah longsor diukur pada lokasi longsor. Pengukuran geometri lereng ini meliputi kemiringan dan ketinggian lereng serta bentuk longsoran. Selanjutnya, pemodelan lereng dibuat menggunakan data properties tanah, geometri sebelum longsor dan geometri setelah longsor.

Analisis tegangan air pori dilakukan menggunakan aplikasi $S E E P / W$. Analisis transient digunakan pada model lereng yang telah dibuat. Kemudian, analisis transient ini dilakukan dari beberapa hari sebelum terjadinya longsor. Analisis ini tegangan air pori menghasilkan kontur tegangan air pori yang disebabkan oleh pengaruh hujan. Selanjutnya, nilai tegangan air pori negatif (suction) dapat diperoleh. Nilai suction ini akan dimasukkan kedalaman grafik hubungan derajat kejenuhan dengan suction, sehingga nilai derajat kejenuhan diperoleh. Kemudian, derajat kejenuhan ini akan dimasukkan kedalam grafik hubungan parameter Bishop stress $(\chi)$ dengan derajat kejenuhan. Sehingga, nilai kohesi, sudut 
gesek internal akibat peningkatan suction $\left(\phi^{b}\right)$, dan kepadatan tidak jenuh ditentukan berdasarkan nilai suction dan parameter kuat geser tanah saat jenuh. Analisis stabilitas lereng dilakukan menggunakan aplikasi SLOPE/W. Pemodelan yang telah dibuat dan hasil analisis tegangan air pori digunakan untuk menghitung faktor keamanan lereng.

\section{HASIL DAN PEMBAHASAN}

\section{Properties Tanah}

Pengambilan sampel tanah dilakukan pada dua lapisan tanah pada lokasi longsor. Sampel tanah ini akan menghasilkan beberapa properties tanah seperti kadar air, berat jenis tanah, kepadatan, porositas, angka pori, permeabilitas, Atterberg limit, analisis saringan dan klasifikasi jenis tanah. Hasil pengujian properties tanah dapat dilihat pada Tabel 1. Berdasarkan sistem klasifikasi unified soil classification system (USCS), tanah lapisan permukaan ini termasuk jenis tanah bergradasi baik-pasir berlanau (SW-SM) dan lapisan dalam ini termasuk jenis tanah pasir berlanau (SM).

Kurva karakteristik air tanah dapat diperkirakan dengan metode modified Kovacs yang tersedia pada $S E E P / W$. Metode ini dikembangkan oleh Aubertin et al. (2013). Metode ini digunakan karena dapat memperkirakan kurva karakteristik air tanah menggunakan properties tanah yang umum (Aubertin et al. 2013). Oleh karena itu, properties tanah yang digunakan untuk memperkirakan kurva karakteristik air tanah meliputi kadar air saat jenuh, D10, D60, dan batas cair. Kurva karakteristik air tanah untuk tanah SW-SM dan tanah SM dapat dilihat pada Gambar 1. Sedangkan, hydraulic conductivity function diperkirakan dengan menggunakan model Van Genucthen yang tersedia pada SEEP/W. Hydraulic conductivity function untuk tanah SW-SM dan tanah SM dapat dilihat pada Gambar 2.

Tabel 1 Data propertis tanah

\begin{tabular}{|c|c|c|c|c|}
\hline No & Parameter Tanah & Satuan & $\begin{array}{c}\text { Pasir bergradasi baik-Pasir } \\
\text { Berlanau (SW-SM) }\end{array}$ & $\begin{array}{c}\text { Pasir Berlempung } \\
\text { (SM) }\end{array}$ \\
\hline 1 & Berat jenis partikel, Gs & - & 2.593 & 2.508 \\
\hline 2 & Kadar air lapang, $w$ & $\%$ & 62.50 & 52.00 \\
\hline 3 & $\begin{array}{l}\text { Derajat kejenuhan lapang, } \\
\mathrm{Sr}\end{array}$ & $\%$ & 86.20 & 92.70 \\
\hline 4 & Porositas, $\mathrm{n}$ & - & 0.70 & 0.63 \\
\hline 5 & Angka pori, e & - & 2.33 & 1.70 \\
\hline 6 & Kohesi saat jenuh, c & $\mathrm{kN} / \mathrm{m}^{2}$ & 0.09 & 0.42 \\
\hline 7 & $\begin{array}{l}\text { Sudut gesek internal saat } \\
\text { jenuh }\end{array}$ & 。 & 6.30 & 9.94 \\
\hline 8 & Permeabilitas, $\mathrm{k}$ & $\mathrm{cm} / \mathrm{det}$ & 0.3500 & 0.0036 \\
\hline 9 & Batas cair, LL & $\%$ & 56.70 & 66.60 \\
\hline 10 & Batas plastis, PL & $\%$ & 32.30 & 34.20 \\
\hline 11 & $\mathrm{D}_{60}$ & $\mathrm{~mm}$ & 1.20 & 0.70 \\
\hline 12 & $\mathrm{D}_{10}$ & $\mathrm{~mm}$ & 0.074 & 0.063 \\
\hline 13 & Residual water content & $\mathrm{m}^{3} / \mathrm{m}^{3}$ & 0.198 & 0.257 \\
\hline 16 & Kepadatan basah, $\gamma_{b}$ & $\mathrm{kN} / \mathrm{m}^{2}$ & 13.82 & 14.82 \\
\hline
\end{tabular}




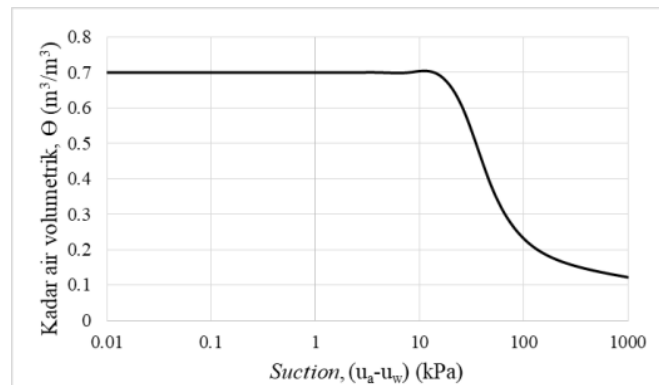

a. Tanah SW-SM

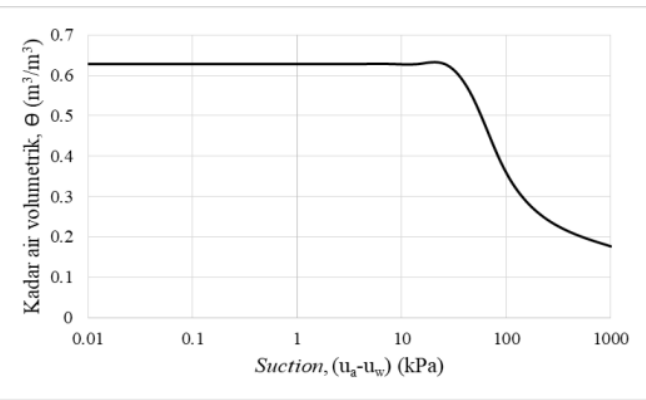

b. Tanah SM

Gambar 1 Kurva karakteristik air tanah

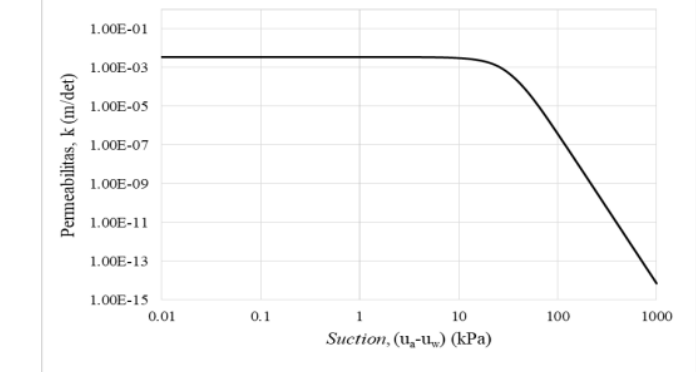

a. Tanah SW-SM

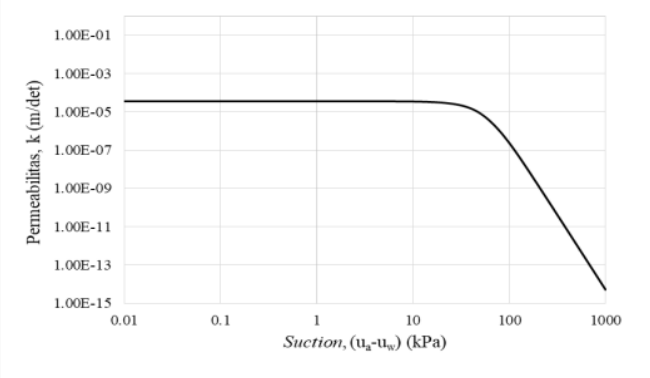

b. Tanah SM

Gambar 2 Hydraulic conductivity function

\section{Hujan}

Curah hujan yang digunakan pada penelitian ini adalah curah hujan jam-jaman dari tanggal 03 Februari 2018 pukul 05.00 WIB hingga 05 Februari 2018 pukul 09.20 WIB. Rentang curah hujan tersebut dipilih karena pada tanggal 02 Februari 2018 tidak terjadi hujan di Puncak, Bogor, Jawa Barat. Intensitas hujan pada rentang waktu tersebut ditampilkan pada Gambar 3.

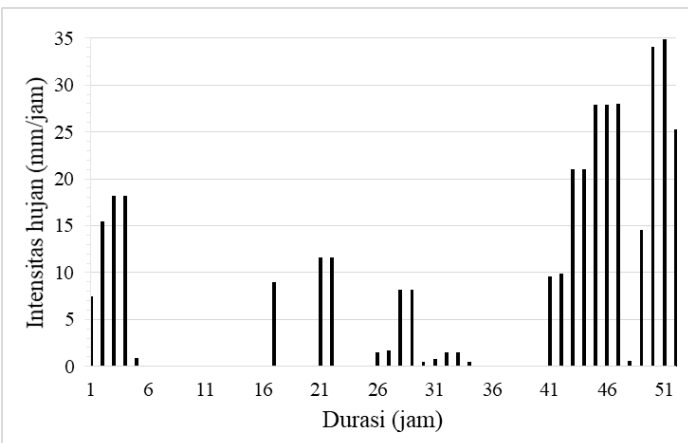

Gambar 3 Intensitas hujan hingga tanggal 05 Februari 2018 pukul 09.20 WIB

Intensitas hujan ini digunakan untuk analisis tegangan air pori. Data curah hujan jam-jaman ini akan dijadikan kondisi batas (boundary condition) pada aplikasi $S E E P / W$. Tipe dari kondisi batas yang digunakan adalah unit flux dalam satuan $\mathrm{m} /$ det. Unit flux dipilih karena unit flux ini dapat digunakan untuk menentukan laju infiltrasi pada permukaan tanah (GeoSlope 2012). Kondisi batas ini juga akan menggunakan fitur seepage face review. Head akan dihitung pada semua bagian yang menggunakan fitur ini. Apabila, pressure head bernilai positif, maka $S E E P / W$ akan menginterprestasikan sebagai air tergenang terbentuk pada bagian permukaannya. Apabila, fitur ini digunakan pada lereng, penggenangan tidak akan terjadi. Sehingga, aliran permukaan akan terjadi (GeoSlope 2012).

Total curah hujan harian untuk tanggal 03 Februari, 04 Februari dan 05 Februari 2018 sebesar $60.4 \mathrm{~mm}, 67.5 \mathrm{~mm}$ dan 274.9 mm. Pada tanggal 03 Februari 2018, intensitas hujan terbesar terjadi pada pukul 06.00 WIB dan 07.00 WIB yaitu 18.2 $\mathrm{mm} / \mathrm{jam}$. Sedangkan, pada tanggal 04 Februari 2018, intensitas hujan terbesar terjadi pada pukul 03.00 WIB dan 04.00 WIB sebesar $11.66 \mathrm{~mm} / \mathrm{jam}$. Intensitas hujan pada tanggal 05 Februari 2018 hingga pukul 09.20 WIB memiliki intensitas lebih dari 20 
$\mathrm{mm} /$ jam kecuali pada jam 06.00 WIB, yaitu sebesar $0.6 \mathrm{~mm} / \mathrm{jam}$. Pada hari tersebut ini, intensitas hujan terbesar terjadi pada pukul $08.00 \mathrm{WIB}$ sebesar $34.9 \mathrm{~mm} / \mathrm{jam}$.

\section{Pemodelan Geometri Lereng}

Model geometri lereng dapat dilihat pada Gambar 4. Model ini memiliki panjang dan tinggi sebesar $50.00 \mathrm{~m}$ dan $43.11 \mathrm{~m}$. Model geometri ini telah disederhanakan dari model yang telah diperoleh dari hasil pengukuran menggunakan alat total station. Penyederhanaan model bertujuan untuk menghasilkan solusi yang dapat dipahami. Selain itu, model geometri yang rumit tidak selalu menghasilkan solusi yang benar dan akurat (GeoSlope 2012). Kemiringan lereng bagian pertama sebesar $47^{\circ}$. Kemiringan ini terjadi sepanjang $22.37 \mathrm{~m}$ dengan ketinggian $16.35 \mathrm{~m}$. Kemudian, kemiringan lereng berubah menjadi $15^{\circ}$.

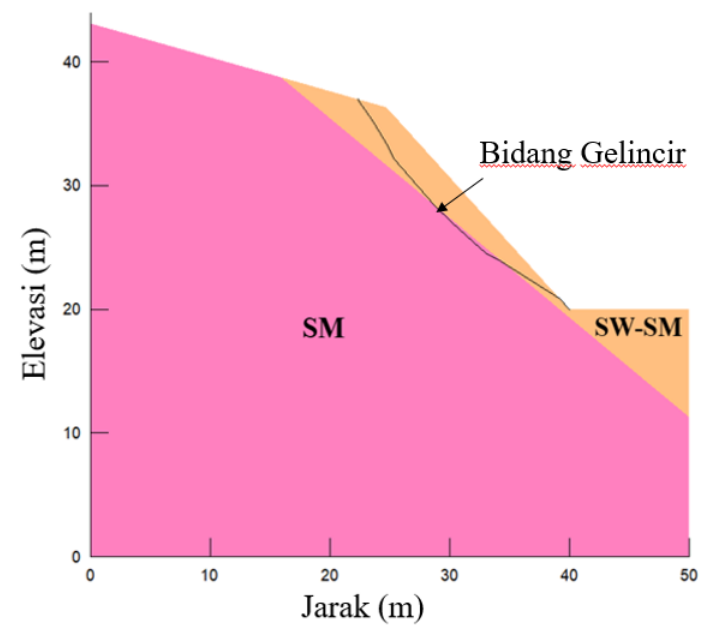

Gambar 4 Model geometri lereng

Longsor yang terjadi ini memiliki kedalaman hingga $3.73 \mathrm{~m}$ dari permukaan lereng. Berdasarkan Gambar 4, longsor ini terjadi pada tanah yang didominasi oleh pasir berlanau bergradasi baik (SW-SM). Total luas longsor yang terjadi sebesar $40.97 \mathrm{~m}^{2}$. Bidang gelincir longsor dimodelkan pada menggunakan fitur fully specified slip surface berdasarkan bidang gelincir yang terjadi di lapangan.

\section{Analisis Tegangan air pori}

Analisis transient dilakukan untuk memperoleh kontur tegangan air pori pada saat intensitas hujan telah dimasukkan kedalam aplikasi $S E E P / W$. Tegangan air pori pada bidang longsor akan digunakan untuk menentukan nilai kohesi untuk tanah SWSM dan SM. Lokasi bidang longsor yang dipilih karena lokasi ini memiliki bidang interface antara dua jenis tanah yang berbeda. Sehingga, tanah yang berbeda jenis ini memiliki nilai $\mathbf{R}_{\text {interface }}$ pada bagian kedua lapisan tanah. Menurut Rifa'i (2009), propertis pada interface berhubungan dengan propertis pada lapisan tanah. Hubungan ini dinyatakan dengan $R_{\text {interface }}$. Nilai ini merupakan faktor reduksi kekuatan. Selain itu, air yang menembus sampai ke bidang longsor akan membuat tanah menjadi licin dan tanah yang berada diatasnya akan bergerak mengikuti sepanjang badan lereng (Atikah et al. 2017). Oleh karena itu, tegangan air pori yang terbentuk pada bidang longsor ini akan digunakan untuk memperoleh parameter kuat geser tanah.

Tegangan air pori pada bidang longsor akan dihasilkan dari analisis transient. Suction merupakan selisih antara tekanan udara pori $\left(u_{a}\right)$ dengan tekanan air pori $\left(u_{w}\right)$ (Sinarta 2016). Tegangan udara pori diasumsikan memiliki nilai sama dengan nol (Uchaipichat 2012). Hasil analisis tegangan air pori menghasilkan grafik hubungan antara durasi hujan dan perubahan derajat kejenuhan dan suction, seperti yang ditampilkan pada Gambar 5. Hasil ini menunjukkan bahwa derajat kejenuhan mengalami peningkatan pada tanah SW-SM dari $32.87 \%$ menjadi $47.86 \%$. Sedangkan, peningkatan pada tanah SM dari $56.56 \%$ menjadi $79.56 \%$. Peningkatan derajat kejenuhan yang cukup besar ini terjadi karena intensitas hujan dari tanggal 03 Februari 2018 hingga 05 Februari 2018 pukul 09.20 WIB memiliki intensitas hujan lebih dari $60 \mathrm{~mm} / \mathrm{hari}$.

Peningkatan derajat kejenuhan pada kedua jenis tanah ini sebanding dengan 
penurunan suction. Penurunan suction yang terjadi dari $100.43 \mathrm{kPa}$ menjadi $57.00 \mathrm{kPa}$. Hal tersebut dapat terjadi karena suction pada rentang ini ingin memasuki zona transisi pada kurva karakteristik tanah.

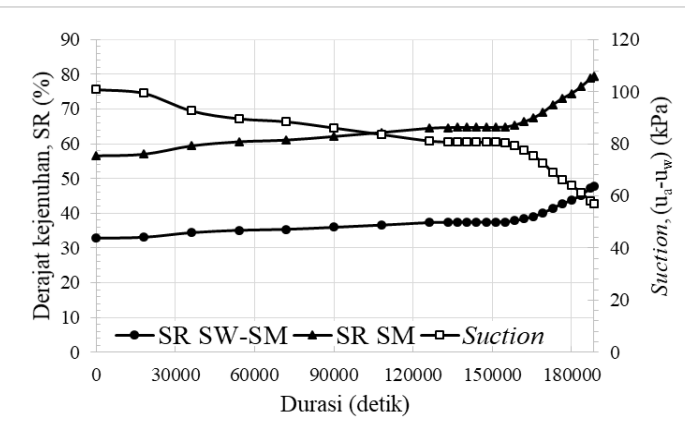

Gambar 5 Grafik hubungan durasi hujan, derajat kejenuhan dan suction

Perubahan nilai suction akibat hujan selanjutnya dihubungkan dengan nilai kohesi tanah, seperti ditunjukkan oleh Gambar 6 dan 7. Penurunan kohesi yang terjadi mengikuti peningkatan derajat kejenuhan. Hal ini terjadi karena penentuan nilai kohesi ini dipengaruhi oleh suction dan sudut gesek internal akibat peningkatan suction $\left(\phi^{b}\right)$.

Perubahan suction ini memiliki hubungan dengan perubahan derajat kejenuhan. Sementara itu, sudut gesek internal akibat peningkatan suction $\left(\phi^{b}\right)$ dipengaruhi oleh perubahan derajat kejenuhan. Semakin besar derajat kejenuhan, maka semakin besar parameter Bishop stress akibatnya sudut gesek internal akibat peningkatkan suction $\left(\phi^{b}\right)$ semakin besar. Seharusnya, peningkatan derajat kejenuhan ini menyebabkan kenaikan nilai kohesi tanah, karena sudut gesek internal akibat peningkatan suction $\left(\phi^{b}\right)$ semakin besar. Hal tersebut tidak terjadi karena penurunan kontribusi suction terhadap kuat geser tanah disebabkan oleh kadar air tanah yang mendekati kadar air residual (Murray dan Sivakumar 2010).

Berdasarkan Gambar 6 dan Gambar 7, penurunan kohesi untuk kedua jenis tanah memiliki pola yang sama. Kohesi pada tanggal 03 Februari 2018 pukul 05.00
WIB hingga tanggal 05 Februari 2018 pukul 09.20 WIB mengalami penurunan pada tanah SW-SM sebesar $1.69 \mathrm{kPa}$ dari $5.76 \mathrm{kPa}$ menjadi $4.01 \mathrm{kPa}$. Sedangkan, penurunan nilai kohesi sebesar $3.48 \mathrm{kPa}$ pada tanah SM dari $12.66 \mathrm{kPa}$ menjadi 9.18 $\mathrm{kPa}$.

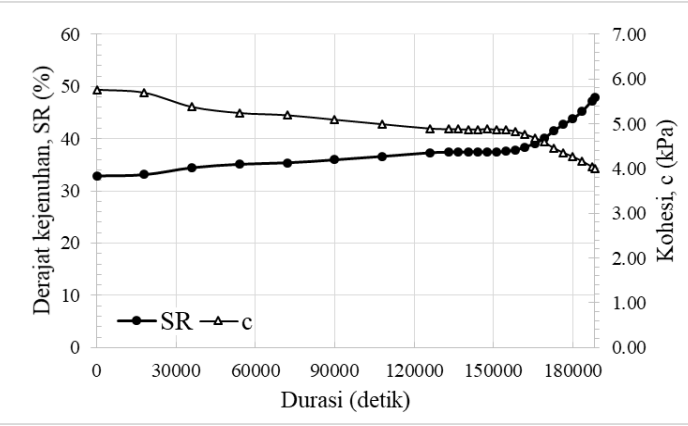

Gambar 6 Grafik hubungan durasi hujan, derajat kejenuhan dan kohesi SW-SM

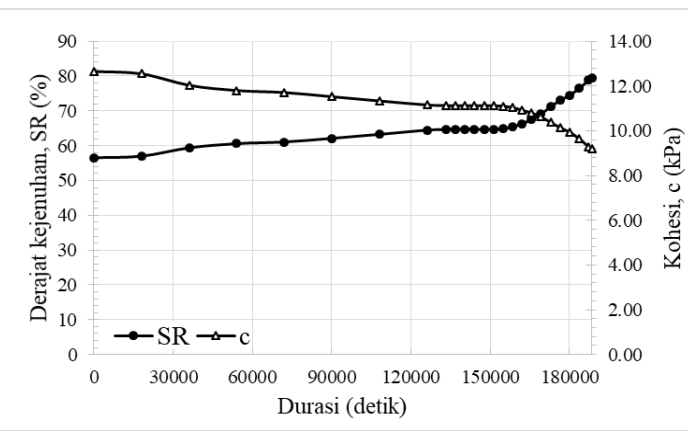

Gambar 7 Grafik hubungan durasi hujan, derajat kejenuhan dan kohesi SM

\section{Analisis stabilitas lereng}

Analisis stabilitas lereng dilakukan untuk mengetahui pengaruh hujan dan perubahan parameter tanah terhadap faktor keamanan lereng (SF). Dari hasil analisis menggunakan aplikasi SLOPE/W diperoleh nilai faktor keamanan awal terjadinya hujan (03 Februari 2018 pukul 05.00 WIB) sebesar 1.602. Selanjutnya nilai ini mengalami penurunan hingga kondisi kritis yaitu SF 1.25 pada tanggal 05 Februari 2018 pukul 03.40 WIB. Kondisi ini termasuk kedalam kategori kritis, karena faktor keamanan sebesar 1.25 (Bowles 1979). Akan tetapi, hujan terus terjadi sehingga nilai faktor keamanan terus mengalami penurunan hingga menjadi 
1.070 pada pukul 09.20 WIB. Hal ini bisa terjadi karena faktor keamanan dapat meningkat secara linier dengan peningkatan nilai kohesi (Rouaiguai et al. 2008). Sehingga, penurunan kohesi ini menyebabkan penurunan faktor keamanan. Faktor keamanan lereng sebesar 1.07 memiliki kemungkinan longsor (Bowles 1979).

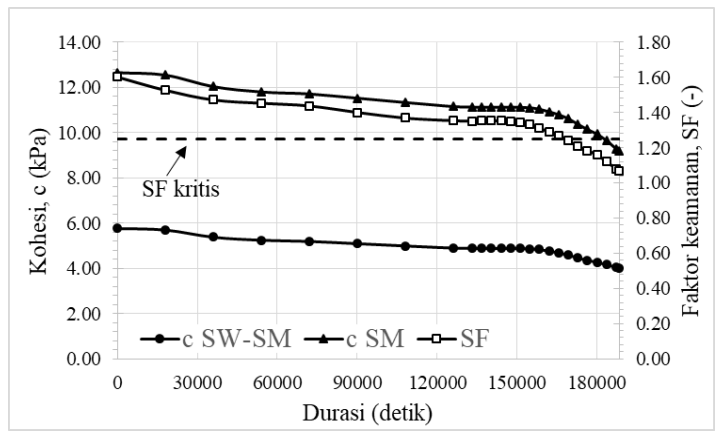

Gambar 8 Grafik hubungan durasi, kohesi dan faktor keamanan

Perubahan nilai faktor aman dari 1.602 menjadi 1.25 membutuhkan durasi hujan yang relatif panjang, yaitu 46 jam 40 menit, sementara itu perubahan status lereng dari kondisi kritis menjadi longsor hanya membutuhkan waktu selama 5 jam 40 menit. Hal ini terjadi karena pada tanggal 05 Februari 2018 pukul 05.00 WIB hingga 09.20 WIB, intensitas hujan cukup besar terjadi pada pukul $07.00 \mathrm{WIB}$ dan 08.00 WIB dengan intensitas hujan sebesar $34.1 \mathrm{~mm} / \mathrm{jam}$ dan $34.9 \mathrm{~mm} / \mathrm{jam}$. Tipe hujan seperti ini efektif memicu longsor pada lereng yang tanahnya mudah menyerap air seperti tanah lempung pasiran dan tanah pasir (Subiyanti et al. 2011).

\section{KESIMPULAN}

Analisis perubahan faktor keamanan lereng akibat pengaruh intensitas dan durasi hujan telah dilakukan pada lokasi longsor di daerah Puncak Bogor. Analisis perubahan faktor keamanan dilakukan menggunakan data hujan sebelum kejadian longsor yaitu pada tanggal 03 Februari 2018 sampai dengan 5 Februari 2018. Pada awal kejadian hujan, faktor keamanan lereng sebesar 1.602. Nilai ini mengalami penurunan menjadi 1.250 setelah penerapan hujan selama 46 jam 40 menit. Selanjutnya, faktor keamanan terus mengalami penurunan hingga mencapai kondisi tidak aman dengan SF 1.070 pada tanggal 05 Februari 2018 pukul 09.20 WIB.

Hasil simulasi ini menunjukkan bahwa durasi yang dibutuhkan menurunkan status kemanan lereng dari kondisi aman menjadi kondisi kritis lebih panjang dari pada waktu untuk kondisi kritis menjadi runtuh, yaitu 46 jam 40 menit berbanding 4 jam 40 menit. Hasil penelitian ini mengkonfirmasi bahwa dalam analisis stabilitas lereng perlu mempertimbangkan hujan yang terjadi beberapa hari sebelum kejadian longsor, sehingga mekanisme terjadinya keruntuhan dan kondisi kritis lereng dapat diketahui sejak dini.

\section{DAFTAR PUSTAKA}

Apriyono A., 2009. Analisis penyebab tanah longsor di Kalitlaga Banjarnegara. Jurnal Dinamika 5(1), pp. 1-5.

Atikah, D., P. T. Juwono, A. P. Hendrawan, 2017. Pengaruh hujan pada stabilitas lereng di jalan tol Gempol-Pandaan. Jurnal Teknik Pengairan 8(1), pp. 79-88.

Aurbertin, M., M. Mbonimpa, B. Bussierr, R. P. Chapuis, A physically-based model to predict the water retention curve from basic geotechnical properties. Canadian Geothecnical Journal 40(6), pp. 1-65.

Bowles, J. E., 1979, Physical and Geothecnical Properties of Soils. Kosaido Printing, Tokyo.

[BPBD] Badan Penanggulangan Bencana Daerah Kabupaten Bogor, 2018. 
Publikasi Kinerja Badan Penanggulangan Bencana Daerah (BPBD) Kabupaten Bogor Tahun 2018. BPBD, Bogor.

GeoSlope International, 2012. Seepage Modelling with SEEP/W. GeoSlope International, Canada.

GeoSlope International, 2017. Heat and Mass Transfer Modelling with GeoStudio 2018, GeoSlope International, Canada

Hasrullah, 2012. Studi pengaruh infiltrasi terhadap stabilitas lereng. Jurnal IlmuIlmu Teknik 5(2), pp. 1-13.

Hutabarat, A. H., Sumono, N. Ichwan, 2015. Kajian laju infiltrasi pada berbagai penggunaan lahan di kebun percobaan Kwala Bekala USU Desa Durin Tonggal Kecamatan Pancur Batu Kabupaten Deli Serdang. Jurnal Rekayasa dan Pertanian 3(4), pp. 503512.

Murray, E. J., V. Sivakumar, 2010. Unsaturated Soils A Fundamental Interpretation of Soil Behaviour. Wiley-Blackwell, West Sussex

Nugroho, S. A., A. I Putra, R. Ermin, 2012. Korelasi parameter kuat geser tanah hasil pengujian triaksial dan unconfined compression strength (UCS). Jurnal Sains dan Teknologi 11(1), pp. 1-10.

Nurdian S, Setyanto, L. Afriani, 2015. Korelasi parameter kekuataan geser tanah dengan menggunakan uji triaksial dan uji geser langsung pada tanah lempung substitusi pasir. Jurnal JRSDD 3(1), pp. 13-26.

Putra, H., Rifa'i, A.,Sujono, J., Silarukmi, A., 2017. Analysis of unsaturated soil parameters as slope stability mitigation. Jurnal Teknologi 79(7-2), pp. 21-27

Rifa'i, A., 2009. Perilaku interaksi tanahgeotekstil terhadap parameter kuat geser. Jurnal Dinamika Teknik Sipil 9(1), pp. 92-100.

Rouaiguia, A., M. A. Dahim, 2008.
Numerical modelling of slope stability analysis. Journal of Engineering and Innovative Technology (IJESIT) 2(3), pp. 553542

Sinarta I. N., 2016. Tegangan pori negatif sebagai parameter stabilitas lereng tanah tak jenuh. Jurnal PADURAKSA 5(1), pp. 31-43.

Subiyanti, H., A. Rifa'i, R. Jayadi, 2011. Analisis kelongsoran lereng akibat pengaruh tekanan air pori di saluran induk Kalibawang Kulonprogo. Jurnal Ilmiah Semesta Teknika 14(1), pp. 15-25.

Uchaipichat, A,. 2012. Infinite slope stability analysis for unsaturated granular soils. Electornic Journal of Geothecnical Engineering 17(30), pp. 361-368 